\title{
High-Frequency Jet Ventilation for HIFU
}

\author{
C. Courbon • P. Bize $\cdot$ M. Chollet Rivier $\cdot$ \\ A. Denys
}

Received: 18 December 2013/Accepted: 3 April 2014/Published online: 1 July 2014

(C) Springer Science+Business Media New York and the Cardiovascular and Interventional Radiological Society of Europe (CIRSE) 2014

\section{Dear Editor,}

We read the review by Muller et al. [1] about the management of respiratory motion in high-intensity focused ultrasound with great interest. As acknowledged by the authors, the motion of abdominal organs due to ventilation is sometimes a main obstacle for interventional radiology [2]. This is a critical issue for HIFU treatment where energy deposits in tissue are small and where precise overlap of each deposit is mandatory. The authors present many solutions more or less adapted to the HIFU technique.

For one solution, the authors use high-frequency jet ventilation as a potentially useful tool. However, careful evaluation of the publications quoted in their paper did not show a study with a prospective organ movement mea-

C. Courbon $(\bowtie) \cdot$ M. Chollet Rivier

Anesthesiology Department, CHUV, Rue du Bugnon,

461001 Lausanne, Switzerland

e-mail: Cecile.Courbon@chuv.ch

M. Chollet Rivier

e-mail: Rivier@chuv.ch

P. Bize · A. Denys

Interventional Radiology Department, CHUV, Lausanne, Switzerland

e-mail: Pierre.Bize@chuv.ch

A. Denys

e-mail: Alban.Denys@chuv.ch surement in humans using this technique. We have recently published a prospective trial on HFJV for percutaneous tumor ablation in 50 patients [3]. In this series, we could demonstrate two important points that are of interest for readers. First, we demonstrated that during HFJV for hepatic and pulmonary radiofrequency ablation (RFA), the mean movement of target close to the diaphragm was $0.3 \pm 0.12,0.3 \pm 0.13$, and less than $3.75 \mathrm{~mm}$ in $\mathrm{x}, \mathrm{y}$, and $\mathrm{z}$ directions respectively (mean $\pm \mathrm{SD}$ ). The movement in the $\mathrm{z}$ direction is probably lower than $3.75 \mathrm{~mm}$, but due to the slice thickness used in our protocol we were not able to give more precise measure in the $\mathrm{z}$ direction. Interestingly in our study, some patients could not be treated using HFJV. They were patients with small tumors highly located in the liver dome area. These lesions could not be reached, because HFJV ventilates the patient in a position near of end expiration. The lesions were then nonvisible under US guidance and a transthoracic approach would have been necessary for needle positioning under CT guidance. This also might be an issue for HIFU, because an ultrasonographic window is necessary for energy deposition in the tissue. This problem was easily solved, because we could switch from HFJV to conventional positive pressure ventilation easily. HFJV, which was claimed by some authors [4] to be a ventilation method that could not be used for long period of time due to a risk of atelectasia and hypercapnia, was actually used for long period of time in our study (mean $2 \mathrm{~h}$ ) without treatment discontinuation due to ventilation problem.

HFJV has the ability to solve all the anesthetic and ventilation issues related to HIFU: a nearly immobile organ even close to the diaphragm, a ventilation method for long procedure. The only remaining problem could be deeply located lesion close to the liver dome that may be obscured by the lung when using this ventilation method. 
Conflict of interest C. Courbon, P. Bize, M. Chollet, and A. Denys have no conflicts of interest to declare.

\section{References}

1. Muller A, Petrusca L, Auboiroux V, Valette PJ, Salomir R, Cotton F (2013) Management of respiratory motion in extracorporeal high-intensity focused ultrasound treatment in upper abdominal organs: current status and perspectives. Cardiovasc Interv Radiol 36:1464-1476

2. Jenne JW, Prusser T, Gunther M (2012) High-intensity focused ultrasound: principles, therapy guidance, simulations and applications. Z Med Phys 22(4):311-322

3. Denys A, Lachenal Y, Duran R, Chollet-Rivier M, Bize P (2014) Use of high-frequency jet ventilation for percutaneous tumor ablation. Cardiovasc Intervent Radiol 37(1):140-146

4. Jorden RC (1988) Percutaneous transtracheal ventilation. Emerg Med Clin N Am 6(4):745-752 